\title{
Control of Precerebellar Neuron Development by Olig3 bHLH Transcription Factor
}

\author{
Zijing Liu, ${ }^{1}$ Hong Li, ${ }^{1}$ Xuemei Hu, ${ }^{1}$ Ling Yu, ${ }^{2}$ Hongbin Liu, ${ }^{2}$ Ruifa Han, ${ }^{3}$ Rita Colella, ${ }^{1}$ George D. Mower, ${ }^{1}$ Yiping Chen, ${ }^{2}$ \\ and Mengsheng Qiu ${ }^{1,3}$ \\ ${ }^{1}$ Department of Anatomical Sciences and Neurobiology, University of Louisville School of Medicine, Louisville, Kentucky 40202, ${ }^{2}$ Department of Cell and \\ Molecular Biology, Tulane University, New Orleans, Louisiana 70117, and ${ }^{3}$ Institute of Urological Surgery, Tianjin Medical University, Tianjin 300211, \\ China
}

The rhombic lip (RL) is the neuroepithelium immediately adjacent to the roof plate of the fourth ventricle, and it gives rise to various brainstem and cerebellar cell types. Our study shows that the bHLH (basic helix-loop-helix) transcription factor Olig 3 is expressed in the progenitors of RL, and ablation of Olig3 significantly affects the development of RL. In Olig3 - / - caudal RL, the expression level of Math1 in the dorsal interneuron 1 (dI1) domain is reduced, and the formation of four mossy-fiber nuclei is compromised; dI2- dI 3 neurons are misspecified to dI4 interneurons, and the climbing-fiber neurons (inferior olive nucleus) are completely lost. In addition, the formation of brainstem (nor)adrenergic centers and first-order relay visceral sensory neurons is also dependent on Olig3. Therefore, Olig3 plays an important role in the fate specification and differentiation of caudal RL-derived neurons.

Key words: bHLH; cell fate; rhombic lip; mossy-fiber nuclei; climbing-fiber nucleus; cerebellum

\section{Introduction}

The rhombic lip (RL) is a specific germinal matrix that is located in the dorsal hindbrain neuroepithelium between the roof plate of fourth ventricle and neural tube. Along the anterior-posterior axis of the rhombomeres, the RL is divided into rostral and caudal parts (Lumsden and Krumlauf, 1996). The rostral RL (rRL) is related to the neuroepithelium of rhombomere 1 (r1) and specifically expresses basic helix-loop-helix (bHLH) transcription factor Math1. The neurons derived from rRL migrate along the rostral rhombic-lip migratory stream and sequentially populate a series of nuclei within the rostral hindbrain and cerebellum, of which most are Math1 dependent (Machold and Fishell, 2005; Wang et al., 2005). In cerebellum, rRL gives rise to glutamatergic external granule layer (EGL) cells, large deep cerebellar nuclei (DCN) neurons, and unipolar brush cells.

The caudal RL (cRL) (r2-r5) comprises the auditory lip and gives rise to the cochlear extramural migratory stream (EMS) to form the cochlear nuclei (CN) (Farago et al., 2006). The generation of ventral $\mathrm{CN}$ and cochlear granule neurons requires Math1 expression (Wang et al., 2005). The more caudal cRL (r6-r8) produce the precerebellar mossy-fiber (MF) nuclei and climbingfiber (CF) nuclei (Ambrosiani et al., 1996; Cambronero and Puelles, 2000). There are four major MF nuclei that project mossy fibers to the EGL and DCN, including the pontine gray nuclei

\footnotetext{
Received Aug. 10, 2008; accepted Aug. 30, 2008.

This work was supported by the National Institutes of Health Grants R21 NS 060033, R01 NS37717, and R01EY016724. We thank Drs. Hirohide Takebayashi, Carmen Birchmeirer, Helena Edlund, and Jane Johnson for generously providing the anti-0lig3, anti-Lbx1, anti-T|x3, anti-Ngn1, and anti-Ptf1a antibodies.

Correspondence should be addressed to Mengsheng Qiu at the above addresses. E-mail: m0qiu001@louisville.edu.

DOI:10.1523/JNEUROSCI.3769-08.2008

Copyright $\odot 2008$ Society for Neuroscience $\quad$ 0270-6474/08/2810124-10\$15.00/0
}

(PGN), reticulotegmental nuclei (RTN), lateral reticular nuclei (LRN), and external cuneate nuclei (ECN). The PGN and RTN migrate in the anterior precerebellar EMS (AES) and settle in the rostral-ventral region of the pons, whereas the LRN and ECN migrate in the posterior precerebellar EMS (PES) and settle in the medial-dorsal and lateral-ventral region of medulla, respectively (Altman and Bayer, 1987a,b,c,d). Loss of Math1 completely inhibits the formation of AES and PES and the generation of four MF nuclei (Wang et al., 2005). In contrast, the inferior olive nucleus (ION) projects climbing fibers to the Purkinje cells, forming the olivocerebellar circuit (Altman and Bayer, 1987a,b,c,d; Sotelo, 2004). The ION migrates from the cRL via the precerebellar intramural migratory stream (IMS) and settles in the medial-ventral region of the medulla (Altman and Bayer, 1987a,b,c,d). The generation of ION is Math1 independent, but the migration of CF neurons requires Ptfla, which is expressed ventral to the Math1 domain (Yamada et al., 2007).

Previous studies showed that Olig3 bHLH transcription factor was expressed in the RL (Takebayashi et al., 2002). In this study, we showed that Olig3 was specifically expressed in dorsal progenitor $1(\mathrm{dp} 1)-\mathrm{dp} 3$ domains of neural progenitor cells in the caudal hindbrain $(\mathrm{r} 6-\mathrm{r} 8)$ and regulated the fates of these neural progenitor cells. In Olig3 mutant hindbrain, the cell fate of dp2 and dp3 progenitors was changed to that of the more ventral interneuron progenitors. The generation of four MF nuclei was markedly reduced. More strikingly, ION CF neurons were completely lost, providing evidence that these neurons may arise from the ventral dorsal interneuron 3 (dI3) domain, which is dependent on both Olig3 and Ptf1a. In addition, development of dorsal Phox $2 b+$ neurons, brainstem (nor)adrenergic centers, and first-order relay visceral sensory neurons was also disrupted. 


\section{Materials and Methods}

Generation of Olig3 knock-out mice. A BAC clone containing Olig3 genomic DNA was purchased from Invitrogen. The Olig3 targeting vector contained a $4 \mathrm{~kb} \mathrm{5}$ arm and a $3.5 \mathrm{~kb} \mathrm{3} 3^{\prime}$ arm at the two ends of neo cassette. Targeting vector was linearized and electroporated into mouse embryonic stem (ES) cells. G418-resistant cells were selected. Genomic DNA from drug-resistant cells was digested with enzyme and analyzed by Southern hybridization using $5^{\prime}$ or $3^{\prime}$ probe for Olig3. Chimeric mice and F1 heterozygous mice were generated from Olig3 mutant ES cell lines. Germline transmission of the target allele was confirmed by both Southern analysis and PCR.

In situ RNA hybridization and immunofluorescent staining. Brain tissues were isolated from embryonic day 10.5 (E10.5)-E18.5 mouse embryos and then fixed in $4 \%$ paraformaldehyde at $4^{\circ} \mathrm{C}$ overnight. After fixation, tissues were transferred to $20 \%$ sucrose in PBS overnight, embedded in OCT media, and then sectioned ( $20 \mu \mathrm{m}$ thickness) on a cryostat. Sections at similar positions from the wild-type and mutant embryos were subsequently subjected to in situ hybridization (ISH) or immunofluorescent staining. ISH was performed as described by Schaeren-Wiemers and Gerfin-Moser (1993) with minor modifications. cDNA templates for ISH were obtained either by reverse transcriptionPCR of postnatal day 0 brain tissues or from a commercial source (Invitrogen), and confirmed by sequencing.

Immunofluorescent staining was performed as follows. After rinsing with PBS, sections were permeabilized in $0.1 \%$ Triton X-100 in PBS for $10 \mathrm{~min}$, rinsed with PBS to remove the excessive Triton, incubated in blocking solution (5\% normal serum in PBS plus 1\% BSA) at room temperature for $1 \mathrm{~h}$, and incubated in diluted primary antibody in blocking solution at $4^{\circ} \mathrm{C}$ overnight. On the next day, sections were washed in PBS three times for $10 \mathrm{~min}$ each, and incubated with the secondary antibody in blocking solution at room temperature for $1 \mathrm{~h}$. After incubation, sections were washed in PBS three times for $10 \mathrm{~min}$ each, before they were mounted in Mowiol mounting medium on glass slides. The staining was examined under a Nikon fluorescence microscope. Rat polyclonal antibody anti-Olig3 was generously provided by Dr. Hirohide Takebayashi. Rabbit polyclonal antibody anti-Ngn1 was kindly provided by Dr. Qiufu Ma. Guinea-pig polyclonal antibody anti-Ptfla was kindly provided by Dr. Jane Johnson. Rabbit polyclonal antibody anti-Ptfla was kindly provided by Dr. Helena Edlund. Anti-Brn3a (1:200; Millipore Bioscience Research Reagents), anti-Mash1 (1:400; BD Biosciences), and anti-Pax2 (1:200; Zymed) were obtained from commercial sources. Guinea-pig polyclonal antibody anti-Lbxl and rabbit polyclonal antibody anti-Tlx3 were kindly provided by Dr. Carmen Birchmeier. The Alexa-488- or Alexa-594-conjugated secondary antibodies were obtained from Invitrogen. The nucleic acid dye DAPI (4',6-diamidine-2' phenylindole dihydrochloride) was obtained from Roche.

Olivocerebellar projection tracing with DiI. Brain tissues were isolated from E18.5 mouse embryos and fixed in 4\% paraformaldehyde. Single or multiple small crystals of DiI were placed in one side of the cerebellar hemisphere far from the midline in E18.5 wild-type or Olig3-/- animals. Tissues were stored in $4 \%$ paraformaldehyde in dark at $37^{\circ} \mathrm{C}$. After 5-6 weeks for DiI diffusion, tissues were transferred to $20 \%$ sucrose in PBS overnight, embedded in OCT media, and then sectioned $(30 \mu \mathrm{m}$ thickness) on a cryostat. The DiI staining was examined under a Nikon fluorescence microscope.

\section{Results}

\section{Olig3 expression pattern in the rhombic lip}

It has been well documented that several nuclei in the hindbrain originate from the rhombic lip. A previous report and our present studies demonstrated that Olig 3 is expressed in the rhombic lip in the entire hindbrain, isthmus area, and the subventricular zone of cerebellum and pons (Fig. 1A,B) (Takebayashi et al., 2002). To investigate the function of Olig3 in the development of hindbrain, we performed detailed studies on the expression pattern of Olig3 in cRL at early embryonic stages by comparing Olig3 expression with various specific interneuron markers. Similar to that in the dorsal spinal cord, the dorsal neuroepithelium in the caudal hindbrain could be divided into several domains along the dorsal-ventral axis based on the expression of multiple interneuron markers (Sieber et al., 2007). At early stages of neural development, Math1 and Ngn1 specifically label the progenitor pool of $\mathrm{dp} 1$ and $\mathrm{dp} 2$, respectively, whereas Tlx 3 marks dI 3 and dI5 interneurons (Gowan et al., 2001; Qian et al., 2002; Sieber et al., 2007). Because the dorsal Ngn1 expression was only detected in cRL at r7-r8 level, which lies between the otic vesicle and cervical spinal cord (Landsberg et al., 2005), we used Ngn1 as the rostral-caudal boundary marker. At E10.5, Olig3 marked the dorsalmost domains (dp1-dp3) of neuroepithelium in the caudal hindbrain and was colabeled with Math1, Ngn1, and Tlx3, respectively (Fig. $1 C-E, G, H)$. There was no Olig3 expression detected in dp4-dp6 domains, from which Pax2-labeled dI4 and dI6 neurons arose (Fig. 1I) (Helms and Johnson, 2003; Mizuguchi et al., 2006). There was a partially overlapping region between Olig 3 and Ptfla in the ventral dp3 domain (Fig. 1C,F,K). The overlapping expression of Olig 3 and Ptfla in the dorsal neuroepithelium became more apparent at E11.5 (Fig. 2A). This overlapping domain appeared to be tightly associated with the generation of Brn3a+ glutamatergic neurons, instead of the Pax2+ GABAergic inhibitory neurons (Fig. $2 B, C$ ), in keeping with the recent observation that Brn3a + CF neurons were labeled by the Ptf1a-Cre fate mapping experiments (Yamada et al., 2007). Olig3 remained to be expressed in the dorsal neural progenitor cells at E12.5, but its expression domain was dorsally retracted (Fig. 2D-F). Together, these studies indicated that Olig3 is selectively expressed in the progenitor pool of the cRL at early stages of neurogenesis, suggesting that Olig3 may be involved in the fate specification and/or migration of the neurons originated from the cRL.

\section{Generation of Olig3 mutant mice}

To elucidate the function of Olig3 in hindbrain development, we performed gene targeting of Olig3 by homologous recombination in ES cells. The targeting vector was designed to replace the entire coding region with the neomycin (neo) gene (Fig. 3A). After electroporation and drug selection, the ES clones harboring homologous recombination were identified by genomic Southern blot with the flanking probes (Fig. 3C). These ES cells were injected into blastocysts, and the targeted alleles were transmitted through germ line. Heterozygous mice were born and mated to obtain homozygous mutant mice. As expected, Olig3 expression was not detected in the Olig3-/- mutants (data not shown). Most Olig3 homozygous mutants died soon after birth, and few could stay alive until $12 \mathrm{~h}$. Olig3-/- mice displayed cyanosis caused by respiratory failure, resembling the congenital hypoventilation syndrome in humans, suggesting that there is a defect in the developing respiratory system, which resides in the brainstem (Shirasawa et al., 2000).

\section{Olig3 regulates the formation of precerebellar mossy-fiber nuclei}

To test the possibility that loss of Olig 3 function may affect the development of RL-derived neurons, we first examined the effects of Olig3 mutation on the correct establishment of brainstem precerebellar nuclei $(\mathrm{PCN})$. There are five major PCN that arise from rhombomere $6-8 \mathrm{cRL}$. The ION provides climbing fibers to the cerebellum. The remaining four are the MF precerebellar nuclei (PGN, RTN, LRN, and ECN), tangentially migrating from the cRL in the precerebellar EMS. Transcription factor Barhll has been used as a generic marker for migrating and mature MF neurons (Bulfone et al., 2000). Expression analyses on E14.5 hindbrain coronal sections revealed that the expression level of 

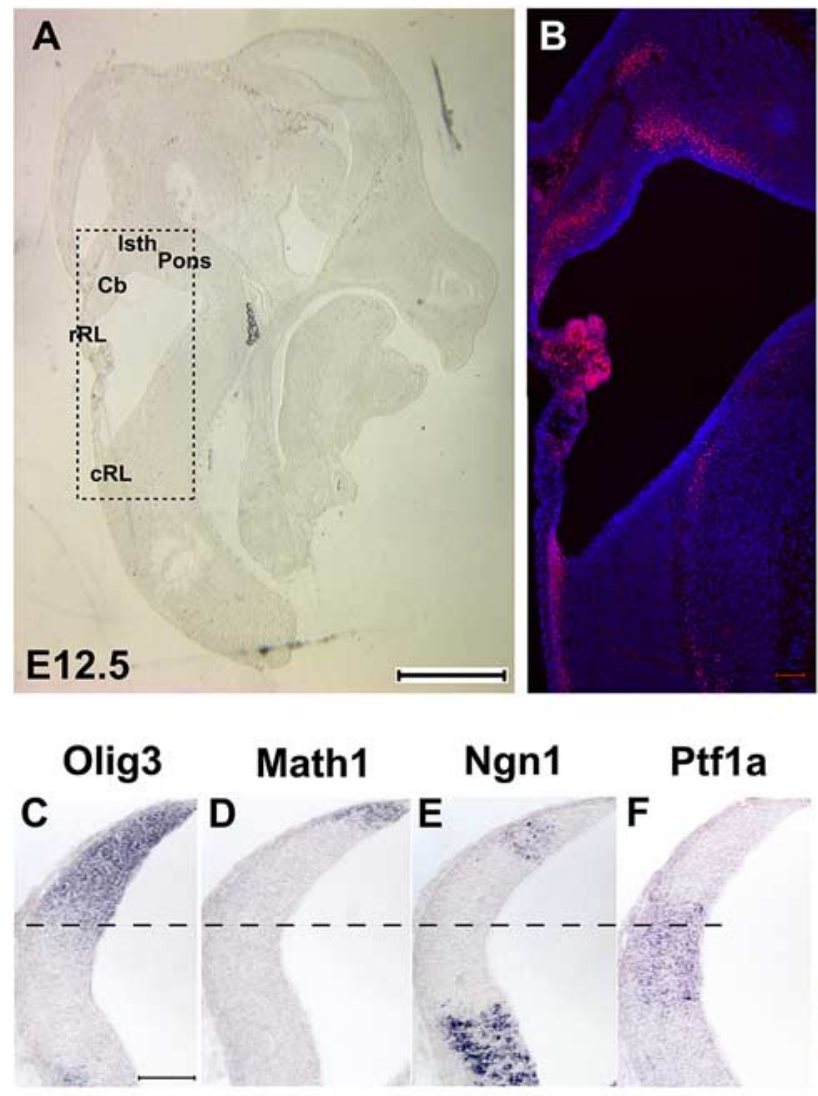

Ngn1/Olig3

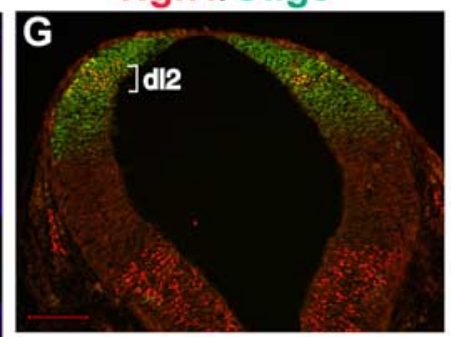

Olig3/Pax2
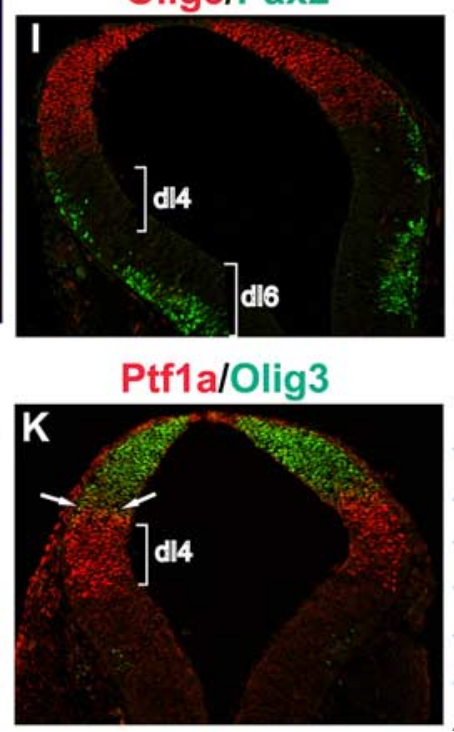
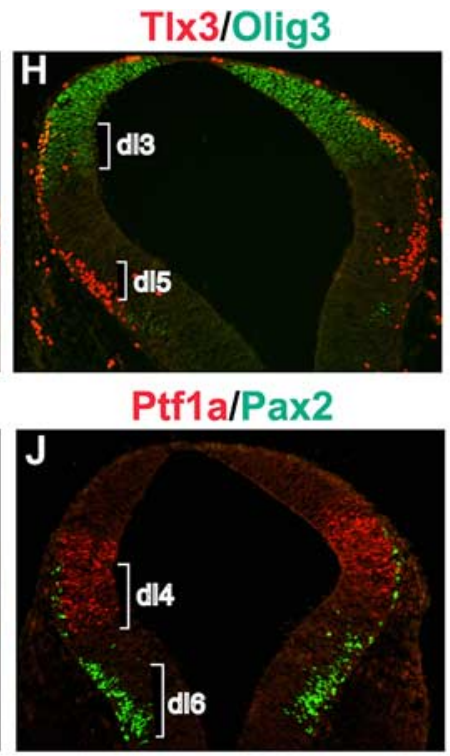

$\mathbf{L}$

Transcription factors Progenitors Neurons Markers

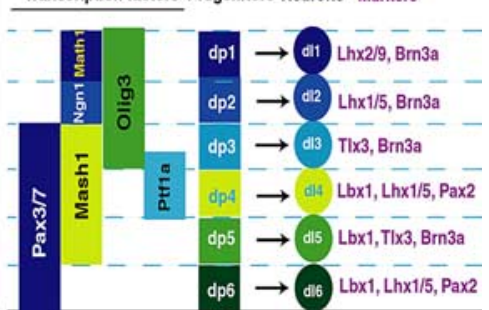

Figure 1. Expression of Olig 3 in the mouse hindbrain. $\boldsymbol{A}$, Unstained bright-field photograph of E12.5 mouse brain sagittal section. $\boldsymbol{B}, 0$ lig3 expression in E12.5 sagittal hindbrain corresponding to the box position shown in $\mathbf{A}$. C-F, In situ hybridization of various progenitor TFs in the dorsal hindbrain at E10.5. All transverse sections are oriented with lateral to the left. Olig 3 expression region included the expression domain of $\operatorname{Math} 1(\boldsymbol{D})$ and $\operatorname{Ngn} 1(\boldsymbol{E})$. There is partial overlap between 0 lig3 $(\boldsymbol{C})$ and $P t f 1 a(\boldsymbol{F})$ expression in dp3 domain. $\mathbf{G}-\boldsymbol{K}$, Double-immunofluorescence analysis of Olig3 expression pattern in E10.5 transverse hindbrain sections at r6 -r8 level. Olig3 expression overlapped with Ngn1 $(\boldsymbol{G})$ and $\mathrm{Tl} \times 3(\boldsymbol{H})$, but not with Pax2 $(\boldsymbol{I})$ in the dorsal hindbrain. Ptf1a was expressed in dp4 and part of dp3 domains $(\boldsymbol{J})$. 0 lig3 and Ptfla were coexpressed in some ventral dp3 progenitors ( $\boldsymbol{K}$, arrows). $L$, Summary of distinct dp domains and dls in which the transcription factors were expressed. Cb, Cerebellum; Isth, isthmus. Scale bars: $\boldsymbol{A}, 1 \mathrm{~mm} ; \boldsymbol{B}, \boldsymbol{C}($ for $\boldsymbol{C} \boldsymbol{F}), \boldsymbol{G}$ (for $\mathbf{G}-\boldsymbol{K}), 100 \mu \mathrm{m}$.

Barh1 in EMS was significantly downregulated in Olig3-1- mutants compared with wild-type tissues (Fig. 4A, $B$ ). As a result, the formation of four MF nuclei was markedly inhibited in Olig3-/- hindbrains, as revealed by Barhll expression in four discrete MF nuclei in E16.5 and E18.5 tissues (Fig. 4E, F,I,J,M,N). Our results showed that transcription factor Zicl is also expressed in MF neurons. Compared with wild-type littermates, Olig3-/- embryos showed apparently reduced Zic1 mRNA expression within the area of the EMS and all four MF nuclei, similar to Barhl1 expression (Fig. 4A-P). Together, these findings demonstrated that Olig3 expression was required for the proper formation of both the EMS and the precerebellar MF nuclei.

\section{Olig3 regulates the formation of the} inferior olive nucleus

ION is the precerebellar CF nucleus, emigrating from the cRL via the IMS and settling in the most ventral region of caudal medulla (Altman and Bayer, 1987a,b,c,d). The migrating and mature CF neurons can be detected by the expression of Brn3a (Fedtsova
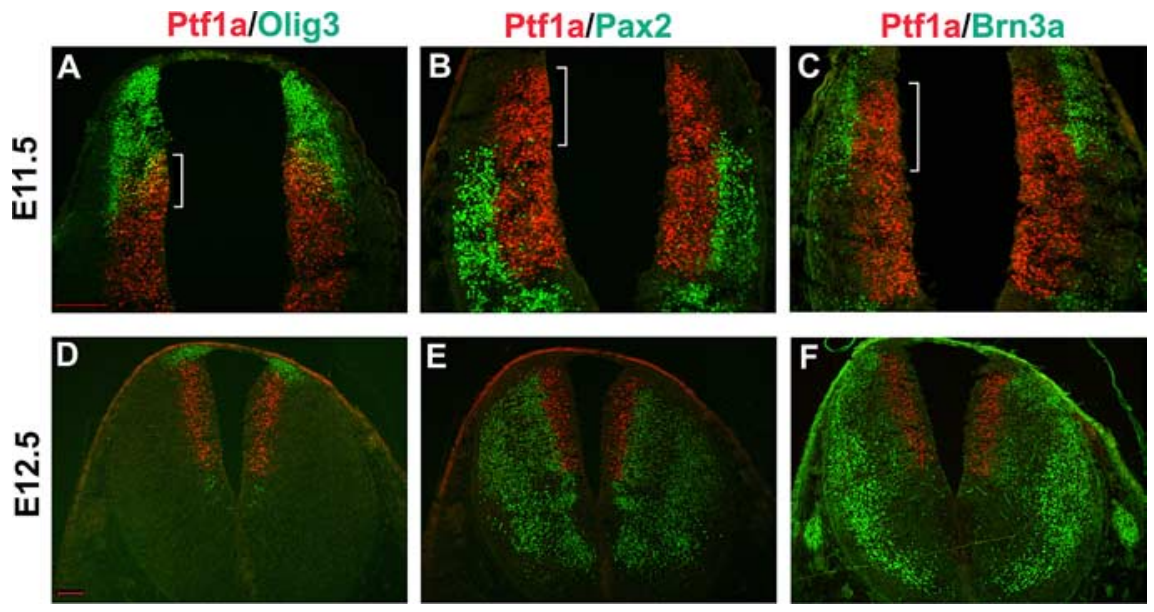

Figure 2. Expression of neural progenitor genes and neuron-specific markers in the dorsal caudal hindbrain. Transverse sections from E11.5 $(\boldsymbol{A}-\boldsymbol{C})$ and $\mathrm{E} 12.5(\boldsymbol{D}-\boldsymbol{F})$ rhombomere 7 were subject to double immunostaining with various progenitor and subtype-specific markers. At E11.5, there was a considerable overlapping between Olig3 and Ptf1a (indicated by bracket; $\boldsymbol{A}$ ), and this overlapping region was associated with the generation of Brn3a+ excitatory neurons (indicated by bracket; $C$ ), but not Pax2 + inhibitory neurons (indicated by bracket; $\boldsymbol{B}$ ). Scale bars: $\boldsymbol{A}$ (for $\boldsymbol{A}-\boldsymbol{C}), \boldsymbol{D}$ (for $\boldsymbol{D}-\boldsymbol{F}), 100 \mu \mathrm{m}$.

and Turner, 1995; Xiang et al., 1996). At E14.5, the Brn3a+ CF neurons in ION were detected at the medulla in the wild-type tissues (Fig. 5A), but not in Olig3-I- mutants (Fig. 5B). The loss of CF neurons in Olig3-deficient mutants was further confirmed 
A

Olig3 locus

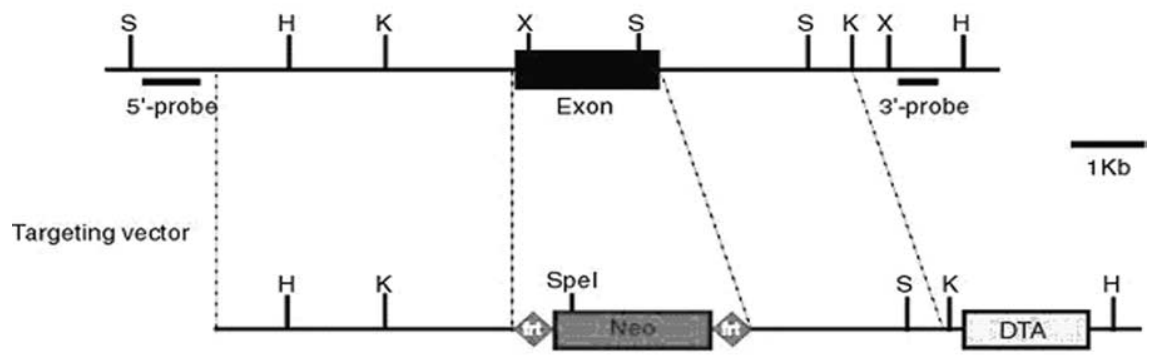

Targeted locus

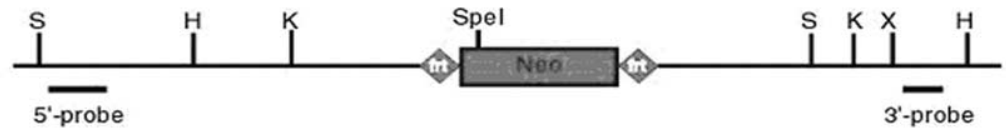

B

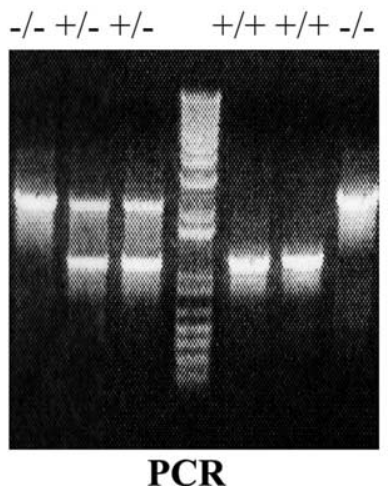

C

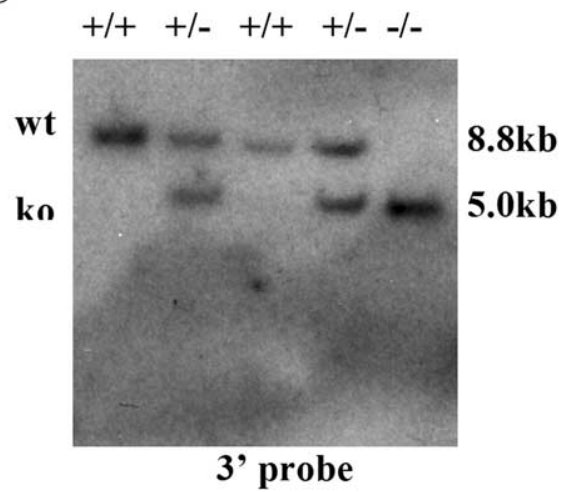

Figure 3. Inactivation of Olig3 by homologous recombination. $\boldsymbol{A}$, Schematic of the strategy for Olig 3 gene targeting. The wild-type Olig 3 locus, targeting vector, and the targeted allele after homologous recombination are shown. $5^{\prime}$ and $3^{\prime}$ probes are used for Southern blot analysis. Neo, Neomycin positive selection marker cassette; DTA, diphtheria toxin gene negative selection marker. $\boldsymbol{B}$, PCR analysis of genomic DNA extracted from wild-type, Olig3 +/-, or Olig3-/ - tails. $\boldsymbol{C}$, Genotyping by Southern blot analyses. Genomic DNA was digested with Hindlll and Spel and hybridized with the $3^{\prime}$ probe. The wild-type allele (wt) appeared as a $8.8 \mathrm{~kb}$ band and the mutant allele (ko) as a $5.0 \mathrm{~kb}$ band.

by the lack of expression of Rph $3 a$ (Fig. 5C,D) and Fgfr2 (data not shown), two other markers for ION neurons (Belluardo et al., 1997; Foletti and Scheller, 2001). The absence of Brn3a and Rph3a expression in Olig3-/- medulla persisted at E16.5 (Fig. $5 E-H)$ and E18.5 (data not shown), indicating that the ION defect was not simply a developmental delay. The loss of ION structure was further confirmed by the lack of Nissl staining in the ION region of the Olig3 mutants (supplemental Fig. S1, available at www.jneurosci.org as supplemental material).

Because no ectopic Brn3a+CF neurons were found in Olig3-/ - medulla, we proposed that ION neurons fail to form possibly as a result of the loss of CF progenitor pool, instead of their incorrect migration route. To examine whether an ectopic olivocerebellar projection existed in Olig3 homozygote mutants, we performed retrograde labeling of axon fibers in the medulla by placing DiI crystals into one side of E18.5 cerebellum and culturing them for 5 weeks in the dark at $37^{\circ} \mathrm{C}$. In the wild-type brains, Purkinje cells incubated with DiI always received the climbing fibers from the contralateral ION (Fig. 5I, K). However, no DiI labeling of climbing fibers and cell bodies was observed in Olig3 mutant brain (Fig. $5 \mathrm{~J}, L$ ), consistent with the idea of the loss of the olivocerebellar circuit. The DiI labeling of the mossy fiber nucleus LRN was detected in the wild-type embryos, but was almost completely lost in Olig3-/- medulla (Fig. 5I-L), in keeping with the dramatic reduction of expression of LRN marker Zic1 (Fig. 4G,H). Based on these results, we concluded that Olig3 expression was indispensable for the generation of CF neurons and LRN mossy fiber neurons.

\section{Olig3 regulates cell fate specification of dp1-dp3}

Previous studies showed that the formation of MF nuclei was dependent on Math1, but the migration of CF neurons was regulated by Ptfla in cRL (Wang et al., 2005; Yamada et al., 2007). Because Olig3 is expressed in the Math1+, Ngn1+, and dorsal part of Ptfla + domains in cRL, it is possible that Olig3 may control the formation of MF nuclei and CF nucleus by regulating the expression of Math1, Ngn1, and Ptfla in the dorsal neural progenitor cells. Consistent with this idea, our expression studies in E10.5 hindbrains revealed a modest reduction of Math1 (we counted $42 \pm 4$ and $28 \pm 6$ Math $1+$ progenitors in control and Olig3-/-, respectively) and Barhl1 expression in dp1 domain (Fig. $6 A-D)$, and a nearly complete loss of dorsal $N g n 1$ expression in the dp2 domain, although the ventral $\mathrm{Ngnl}$ expression was not affected (Figs. 6E,F, $7 E, F$ ). The expression of Lmxla resides immediately dorsal to Math1 and marks the roof plate. Lmxla expression was similar in control and Olig3-/- embryos (Fig. $6 K, L$ ). Interestingly, the expression pattern of $\mathrm{Neo}$ in Olig3-1- mutants was nearly identical to that of the endogenous Olig3 gene in the wild-type embryos (Fig. 6G,H), indicating that Olig3 mutation did not affect the initial allocation and survival of neural progenitors in RL.

Remarkably, Ptf1a was upregulated and expanded dorsally into the dorsal dp3 and dp2 domains in Olig3-null hindbrain (Fig. 6I,J). Ectopic expression of Pax2 (dI4 and dI6 marker) and Lbx1 (dI4-dI6 marker) was also detected at the positions of dI2 and dI3 interneurons (Fig. 7A-D). The dorsal expansion of Ptfla and Pax 2 expression was accompanied by the reduced expression of Brn3a in dI1-dI3 dorsal interneurons and the absence of Brn3a+ IMS in the Olig3-/- hindbrain (Fig. $7 A, B$; supplemental Fig. S2, available at www.jneurosci.org as supplemental material). In contrast, Brn3a + dI5 interneurons persisted in the mutant embryos. In addition, Olig 3 mutation resulted in the loss of Tlx3 + dI3 interneurons, but not Tlx3 + dI5 neurons (Fig. 7G,H). Expression of Mash1 (dp3-dp5 marker) was not affected by loss of Olig3 (Fig. $7 I, J$ ). Together, these observations indicated that in the absence of Olig3 expression, Brn3a+dI2 and dI 3 neurons were respecified to Pax $2+\mathrm{dI} 4$ neurons. In other words, whereas the Ptf1a+ domain gives rise to both Brn3a+ and Pax2+ neu- 


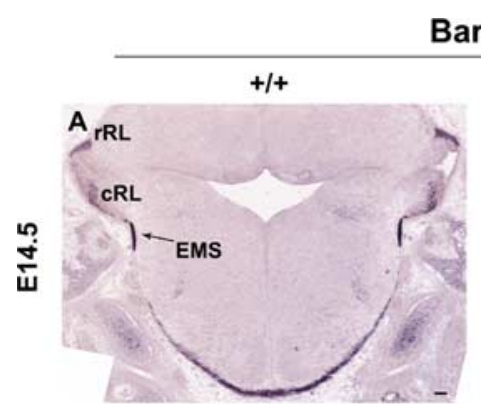

Barhl1
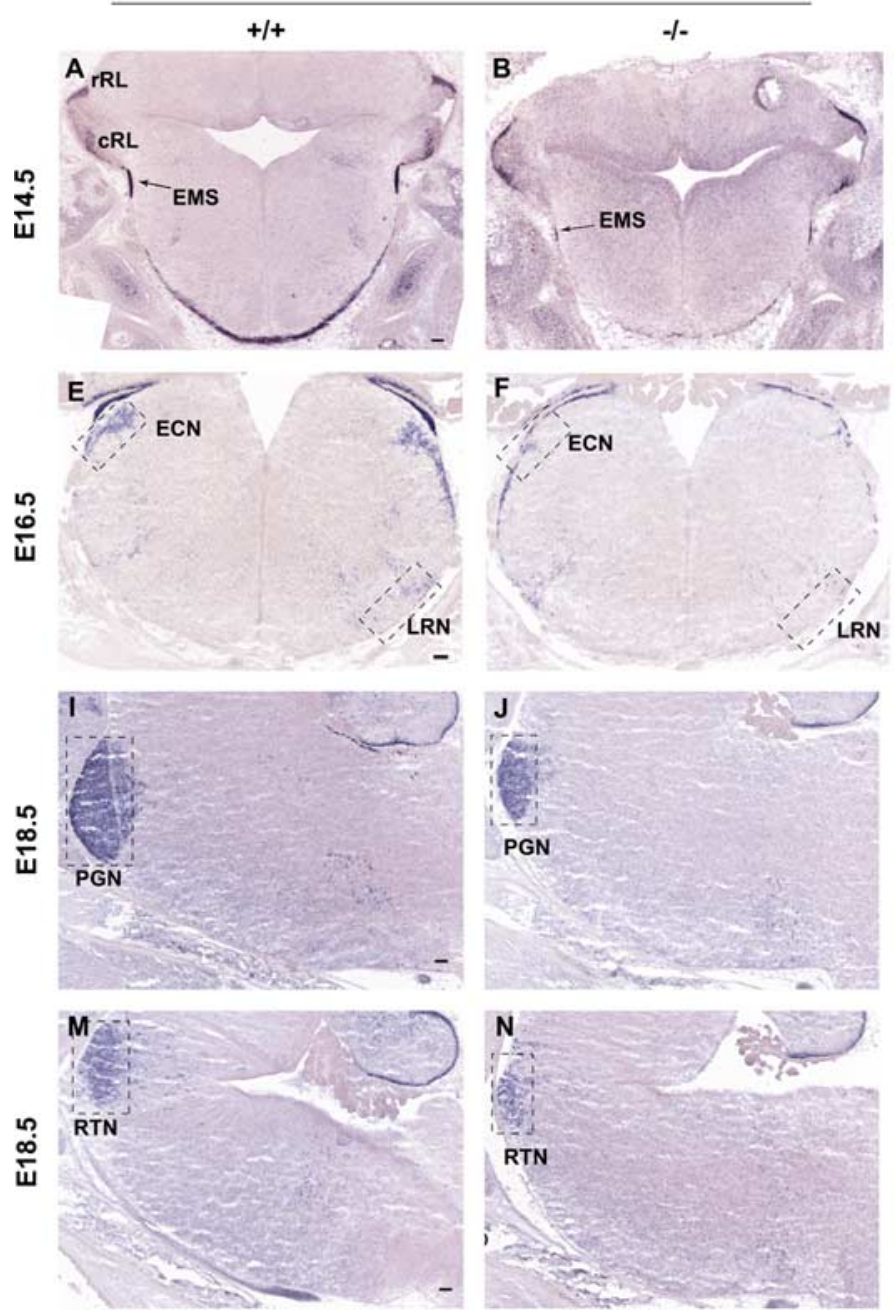
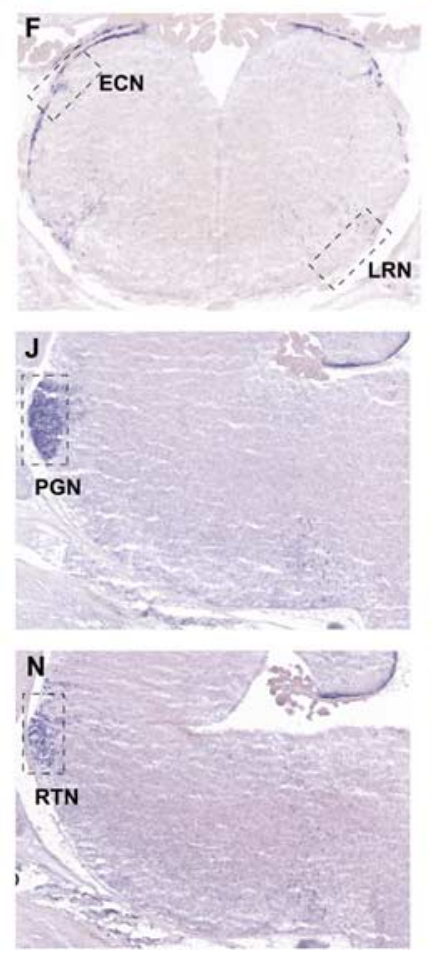

Zic1
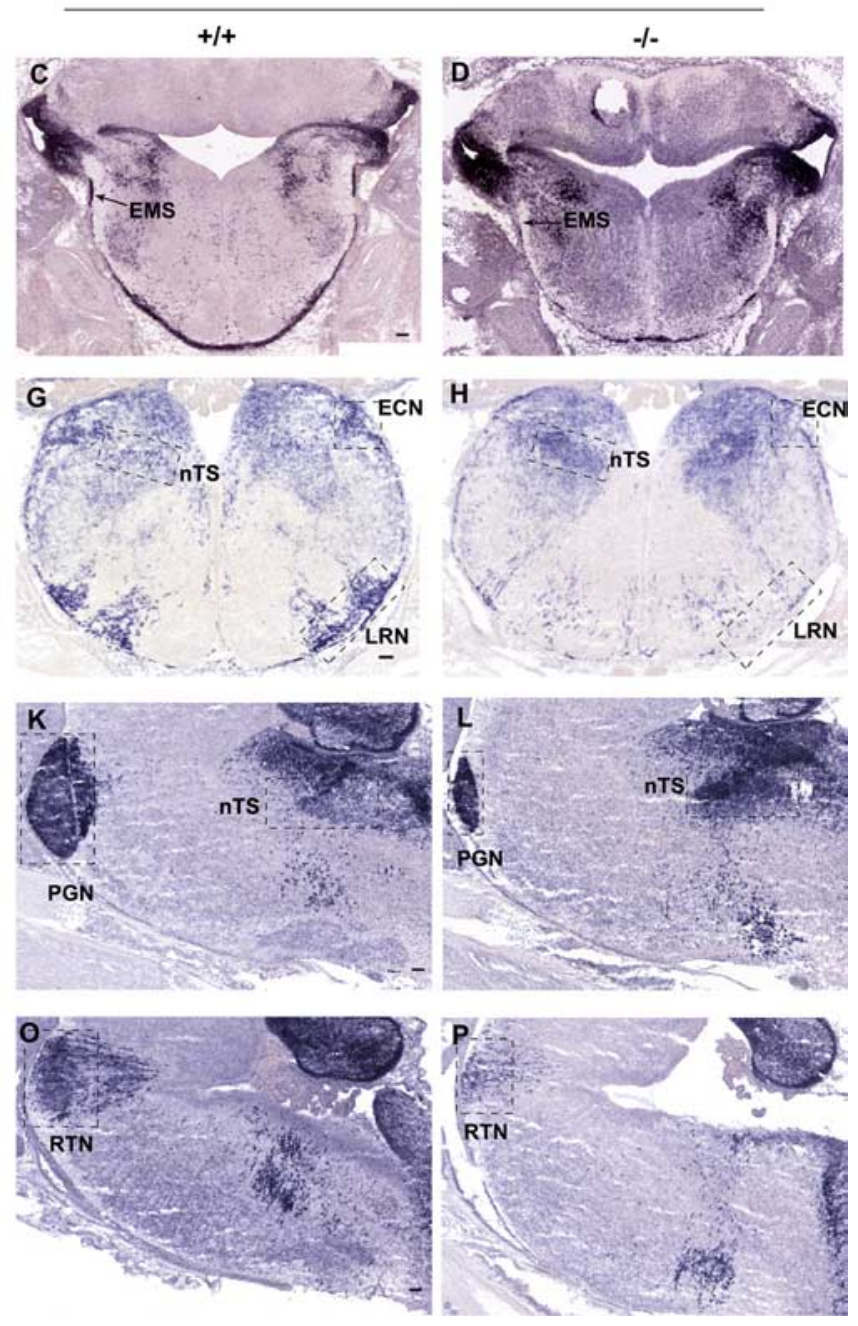

Figure 4. Olig3 mutation affected the generation of precerebellar mossy-fiber nuclei. $\boldsymbol{A}-\boldsymbol{H}$, Coronal sections from E14.5 and E16.5 hindbrain tissues were examined by in situ hybridization for expression of Barh/1 $(\boldsymbol{A}, \boldsymbol{B}, \boldsymbol{E}, \boldsymbol{F})$ and Zic $1(\boldsymbol{C}, \boldsymbol{D}, \boldsymbol{G}, \boldsymbol{H})$. Both of these genes were expressed in the migrating and mature mossy-fiber neurons. Loss of Olig3 function significantly downregulated the expression level of these two genes in the EMS and reduced the size of the mature mossy-fiber nuclei, LRN and ECN. $\boldsymbol{I}-\boldsymbol{P}$, E18.5 sagittal sections with rostral to the left. $\boldsymbol{I}, \boldsymbol{J}, \boldsymbol{M}, \boldsymbol{N}$, Sections were labeled with Barh/1 probe. $\boldsymbol{K}, \mathbf{L}, \mathbf{O}, \boldsymbol{P}$, Sections were stained with Zic1 probe. Olig3-null embryos displayed the reduced size of two other mossy-fiber nuclei, PGN and RTN. Ectopic Zic1 expression was detected in the $\mathrm{nTS}$ area $(\boldsymbol{G}, \boldsymbol{H}, \boldsymbol{K}, \boldsymbol{L})$. Scale bars: $\boldsymbol{A}$ (for $\boldsymbol{A}, \boldsymbol{B}), \boldsymbol{C}($ for $\boldsymbol{C}, \boldsymbol{D}), \boldsymbol{E}$ (for $\boldsymbol{E}, \boldsymbol{F}), \boldsymbol{G}$ (for $\boldsymbol{G}, \boldsymbol{H}), \boldsymbol{I}($ for $\boldsymbol{I}, \boldsymbol{J}), \boldsymbol{K}($ for $\boldsymbol{K}, \boldsymbol{L}), \boldsymbol{M}($ for $\boldsymbol{M}, \boldsymbol{N}), \boldsymbol{O}($ for $\mathbf{O}, \boldsymbol{P}), 100 \mu \mathrm{m}$.

rons in wild-type mice, the expanded Ptfla + domain in Olig3-/- mice only produces Pax2+ neurons.

\section{Olig3 is required for proper formation of the brainstem (nor)adrenergic centers and visceral sensory neurons}

Both relay visceral sensory and (nor)adrenergic neurons in the brainstem play crucial roles in regulating respiration pattern and cardiovascular activities, and these two classes of neurons originate from dp3 domain (Qian et al., 2001, 2002). Our studies show that Olig $3-1-$ mice die from respiratory failure, suggesting that Olig3 may affect the generation of these two types of neurons. Because Phox $2 b$ is essential for formation of brainstem (nor)adrenergic centers and proper development of many visceral sensory neurons (Morin et al., 1997; Pattyn et al., 1999, 2000), we performed a detail examination of Phox $2 b$ expression in Olig3deficient hindbrains. Dorsal Phox $2 b$ expression was completely inhibited in E11.5 and E12.5 Olig3-/- mutants, whereas its ventral expression in the dorsal motor nucleus of vagus ( $\mathrm{dmnX}$ ) was normal (Fig. $8 A-D$ ). At later stages, Phox $2 b$ expression was completely eliminated in the prospective nucleus of the solitary tract (nTS) area in the Olig3-/- hindbrain (Fig. 8E,F,I,J). The first- order relay visceral sensory neurons in the nTS receive signals generated from peripheral chemoreceptors and pulmonary stretch receptors and then influence respiration rates (Blessing, 1997). In addition, the expression level of Phox $2 b$ was reduced in the pons as well (Fig. $8 I, J)$. In contrast, Phox $2 b$ expression in other brainstem structures was not affected, including the dmnX and nucleus ambiguus (Fig. 8E,F,I,J). Instead, ectopic Zic1 expression was detected at the nTS area in E16.5 and E18.5 Olig3-/- medulla (Figs. 4G,H, 8G,H). To determine the stages when ectopic migration of $Z i c 1+$ neurons occurs, we examined Zic1 expression in Olig3 mutant embryos at earlier stages. At E10.5, Zic1 expression was normal in the ventricular zone throughout the entire dorsal hindbrain (data not shown). At E12.5, Zic1 + neurons derived from dp1 and dp4 domains formed two ventrally migratory streams in wild-type embryos, whereas $\mathrm{Zicl}+$ neurons from the entire $\mathrm{dp} 1-\mathrm{dp} 4$ region were able to migrate ventrally in Olig3-/ - hindbrains (supplemental Fig. $S 3 A-D$, available at www.jneurosci.org as supplemental material), further supporting the notion that dI2-dI3 neurons are misspecified to dI4 interneurons and behave like dI4 neurons. However, misspecified dorsal interneurons still took their migra- 

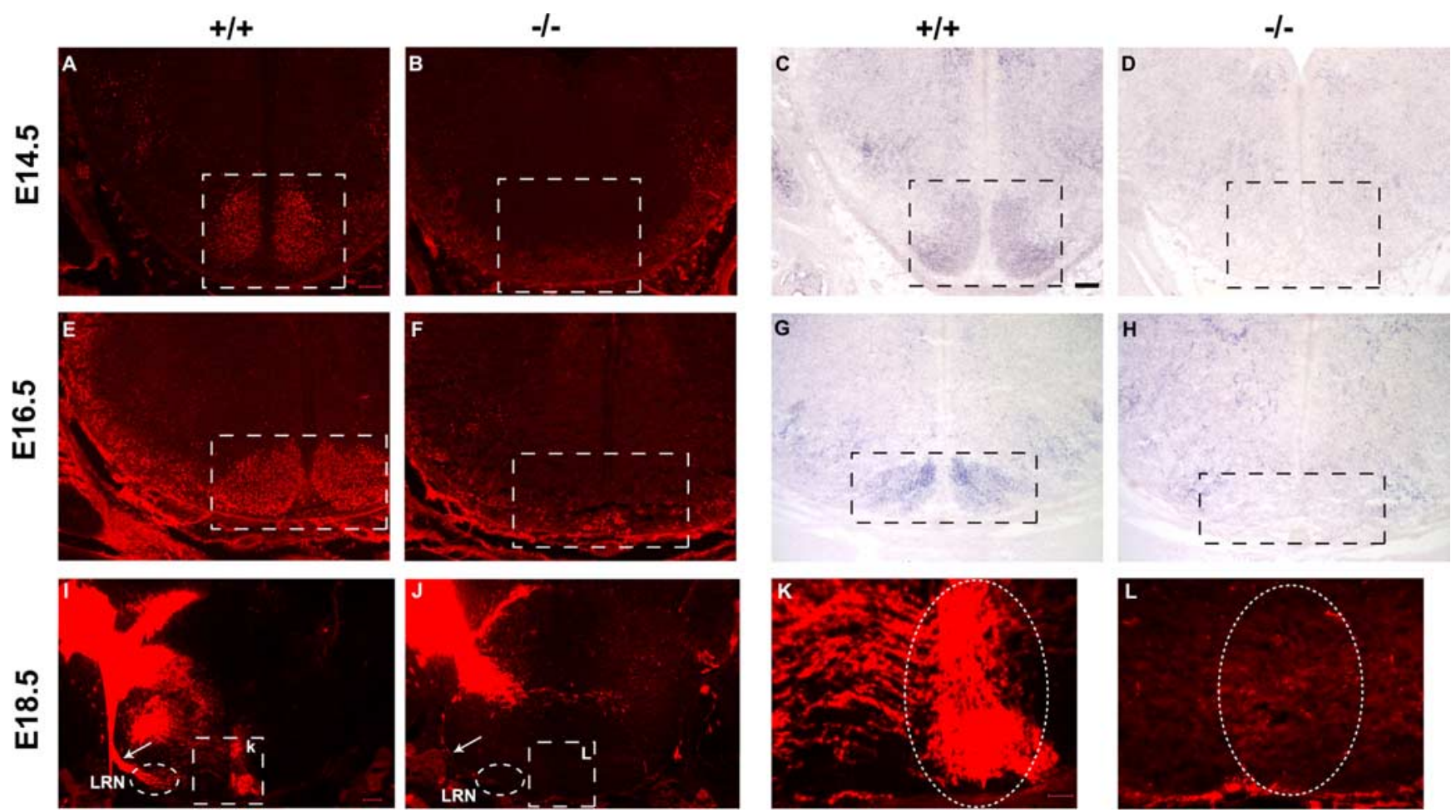

Figure 5. The 0lig3 - I- mutant lost the precerebellar climbing-fiber neurons. $\boldsymbol{A}-\boldsymbol{H}, \mathrm{E14.5}(\boldsymbol{A}-\boldsymbol{D})$ and $\mathrm{E} 16.5(\boldsymbol{E}-\boldsymbol{H})$ coronal medulla sections were subjected to immunostaining with anti-Brn3a antibody $(\boldsymbol{A}, \boldsymbol{B}, \boldsymbol{E}, \boldsymbol{F})$ or in situ hybridization with Rph3a probe $(\boldsymbol{C}, \boldsymbol{D}, \boldsymbol{G}, \boldsymbol{H})$. Both genes were expressed in the climbing-fiber neurons. ION comprised of climbing-fiber neurons was lost in Olig3-null medulla. $I-L$, Dil labeling was used to examine the formation of the olivocerebellar projection in E18.5 tissues. Dil crystal was placed into one side of wild-type cerebellum, and projections (arrow) to the contralateral ION (circled area) were detected $(\boldsymbol{I}, \boldsymbol{K})$. However, the formation of the Dil labeling olivocerebellar projection was not detected in the Olig $3-/-$ mutant $(\boldsymbol{J}, \boldsymbol{L})$. In addition, Dil labeling of LRN neurons was drastically reduced as well in the mutant (small circled area; $I, J)$. The dashed boxes in $\boldsymbol{A}-\boldsymbol{J}$ outline the ION area. $\boldsymbol{K}, \boldsymbol{L}$, High-magnification images of $I$ and $\boldsymbol{J}$. Scale bars: $\boldsymbol{A}$ (for $\boldsymbol{A}, \boldsymbol{B}, \boldsymbol{E}, \boldsymbol{F}), \boldsymbol{C}($ for $\boldsymbol{C}, \boldsymbol{D}, \boldsymbol{G}, \boldsymbol{H}), 100 \mu \mathrm{m} ; \boldsymbol{I}($ for $\boldsymbol{I}, \boldsymbol{J}), 200 \mu \mathrm{m} ; \boldsymbol{K}$ (for $\boldsymbol{K}, \boldsymbol{L}), 50 \mu \mathrm{m}$.

tion path to the nTS area, which is normally occupied by Phox $2 b+$ neurons derived from dI3 domain (Fig. 8G,H) (Qian et al., 2001). Consistent with this idea, ectopic expression of Viaat, GABAergic neuron marker, was detected at the nTS area in E18.5 Olig3-deficient embryos (supplemental Fig. S3E-H). This finding is in keeping with the observations that Ptfla promoted neural precursors to differentiate into GABAergic neurons (Hoshino et al., 2005; Mizuguchi et al., 2006) and was ectopically expressed in dp2 and dp3 domains in Olig3-/ - hindbrain (Fig. 6I,J).

Our results also showed that loss of Olig 3 function affected the formation of (nor)adrenergic centers. The generation of the $\mathrm{A} 1 / \mathrm{C} 1$ and $\mathrm{A} 2 / \mathrm{C} 2$ clusters in the medulla was completely absent in Olig3-1- brainstems, as indicated by the lack of expression of tyrosine hydroxylase (TH) (Fig. $8 K, L)$. In summary, loss of Olig3 function completely inhibited the generation of Phox $2 b+$ neurons derived from the $\mathrm{CRL} \mathrm{dp} 3$ domain and disrupted the formation of brainstem (nor)adrenergic centers and first-order relay visceral sensory neurons.

\section{Discussion}

In this study, we present evidence that Olig3 is primarily expressed in RL cells in the developing hindbrain and that its expression is important for the fate specification of RL progenitor cells. In the absence of Olig3 function, development of precerebellar neurons derived from the caudal RL is either reduced or completely inhibited. Additionally, Olig3 plays a critical role in regulating the formation of the central respiratory system.

Olig 3 is predominantly expressed in RL cells in the hindbrain The RL was first reported as the germinal zone immediately adjacent to the roof plate of the fourth ventricle through morpho- logical studies (His, 1891). The diversity of neurons in the mature brain is proposed to be generated from this neuroepithelium and to migrate to their destination. Although many attempts have been made, the exact distinction between the RL and the adjacent neuroepithelium still remains unclear. Our studies suggest that Olig 3 can be used as a candidate molecular marker for labeling RL cells based on the following observations. (1) Olig3 is expressed in the RL throughout the anterior-posterior axis of the rhombomere (Fig. 1 B) (Takebayashi et al., 2002). (2) No Olig3 expression is detected in the roof plate, and the mutation of Olig 3 is not related to the development of the roof plate (Fig. $6 G, K, L)$. (3) Olig3 is expressed in the Math1+ and dorsal part of Ptfla + domains in CRL, from which MF neurons and CF neurons arise (Fig. 1). (4) Olig3 mutation reduces the generation of MF nuclei and completely inhibits the formation of CF nucleus. Together, these observations strongly suggest that Olig3 predominantly labels RL progenitor cells in the entire hindbrain.

\section{Origin and molecular specification of ION neurons in the caudal hindbrain}

Our data showed that Olig3 is specifically expressed in dp1-dp3 domains of the caudal hindbrain at r6-r8 level (Fig. $1 C-K$ ). It is well known that Math1 is specifically expressed in the dp1 domain and determines the cell fate of dI1 neurons that substantially form the precerebellar MF neurons (Wang et al., 2005). Loss of Olig3 leads to a modest downregulation of Math1 expression (Fig. 6A,B) and partial reduction of four MF nuclei in the brainstem (Fig. 4). Although the origin of the MF neurons has been well defined, it remains unclear from which region of $\mathrm{cRL}$ the precerebellar CF neurons are derived. Classical ablation experiments indicated that removal of the dorsal third of the neuroep- 

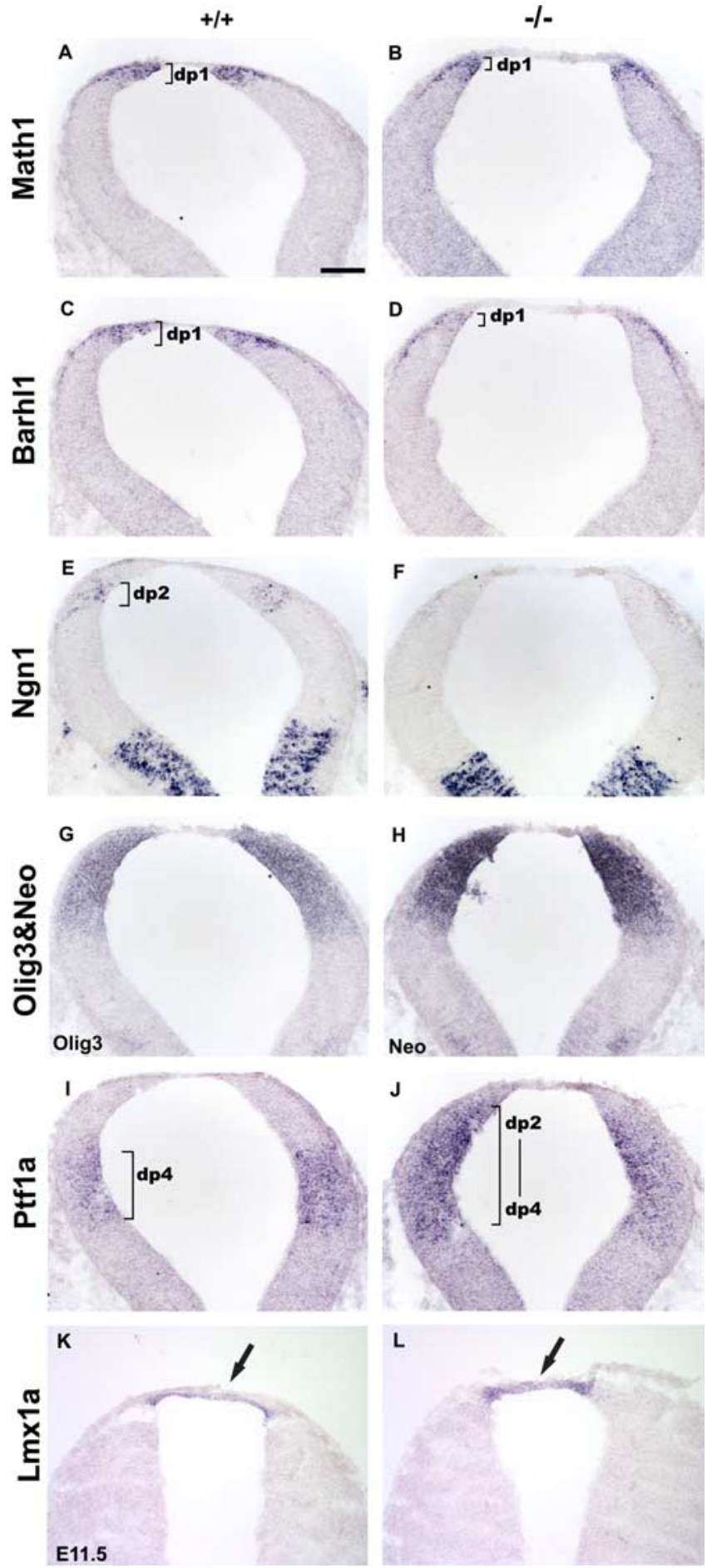

Figure 6. Altered gene expression in CRL of Olig3-null embryos. $\boldsymbol{A}-\boldsymbol{L}$, Hindbrain sections from E10.5 embryos at the CRL level were subjected to in situ hybridization with riboprobes for $\operatorname{Math} 1(\boldsymbol{A}, \boldsymbol{B}), \operatorname{Barh} / 1(\boldsymbol{C}, \boldsymbol{D}), \operatorname{Ngn} 7(\boldsymbol{E}, \boldsymbol{F}), \operatorname{Olig} 3(\boldsymbol{G}), \operatorname{Neo}(\boldsymbol{H})$, Ptfla $(\boldsymbol{I}, \boldsymbol{J})$, and Lmx1a $(\boldsymbol{K}, \boldsymbol{L})$. Loss of Olig3 significantly downregulated the expression level of Math1, Ngn1, and Barhl1, whereas Ptf1a expression was ectopically expanded into dp2-dp3 domains. The expression pattern of $\mathrm{Neo}$ in Olig3 mutant was the same as that of Olig3 in wild-type controls $(\boldsymbol{G}, \boldsymbol{H}) . \boldsymbol{K}, \boldsymbol{L}$, Arrows indicate $L m \times 1 a$ expression in the roof plate. Scale bar, $100 \mu \mathrm{m}$.

ithelium in the caudal hindbrain could completely inhibit the formation of ION comprised of CF neurons (Harkmark, 1954). Our results suggested that $\mathrm{CF}$ neurons are derived from the Olig3-expressing domains. In Olig3 mutant embryos, dI2 and dI3 $\mathrm{Brn} 3 \mathrm{a}+$ neurons were not produced, in parallel to the complete
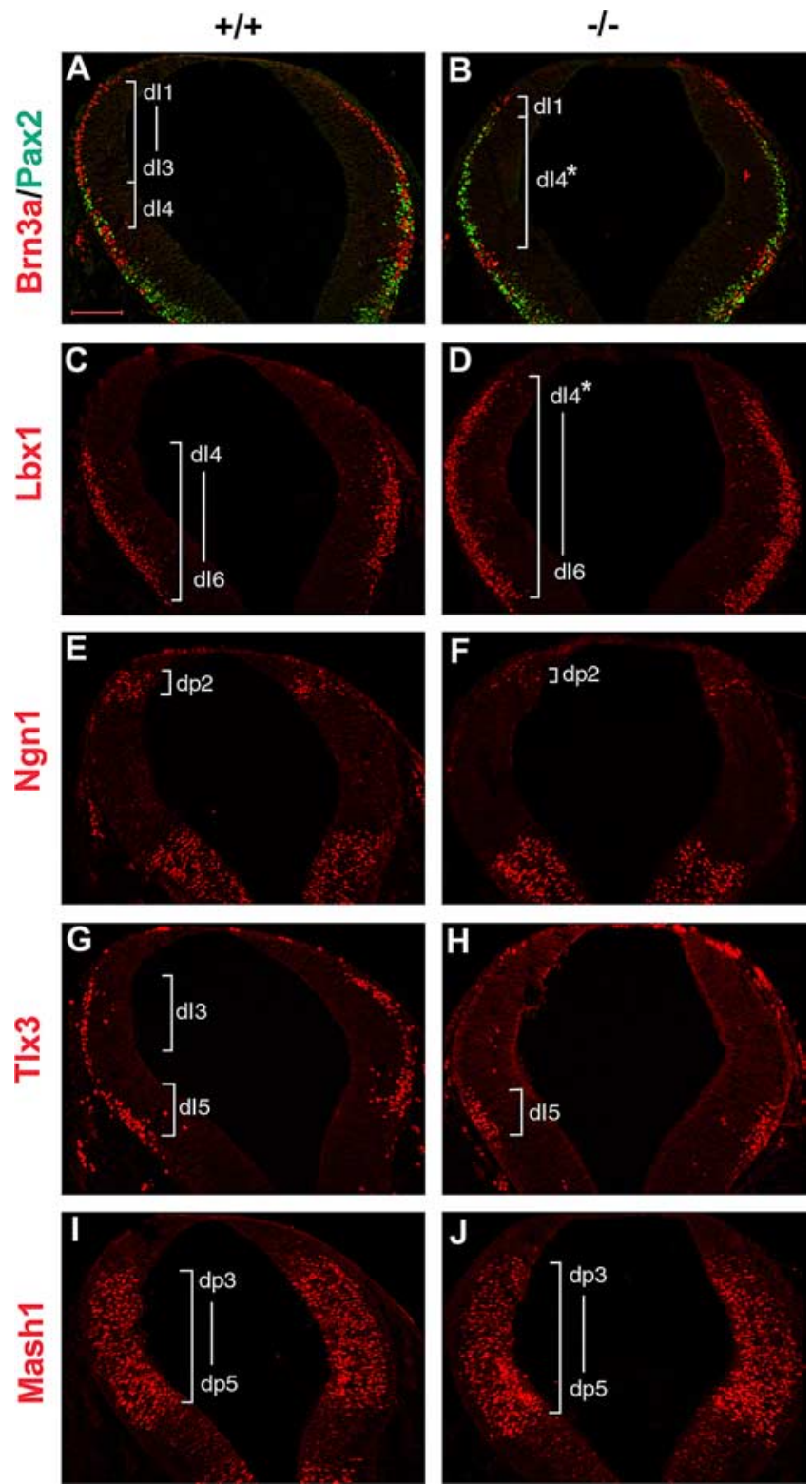

Figure 7. Olig3 is important for the specification of $C R L . A-J$, Coronal sections of E10.5 CRL were assessed by immunostaining with $\operatorname{Brn} 3 \mathrm{a}$ and $\operatorname{Pax2}(\boldsymbol{A}, \boldsymbol{B}), \operatorname{Lbx} 1(\boldsymbol{C}, \boldsymbol{D}), \operatorname{Ngn} 1(\boldsymbol{E}, \boldsymbol{F}), \operatorname{T|} \times 3(\boldsymbol{G}$, $\boldsymbol{H})$, and Mash1 $(\boldsymbol{I}, J)$. The Olig3 $-/-$ mutant lost the expression of Brn3a in dl2 $-\mathrm{dl} 3$ neurons and $\mathrm{Tl} \times 3$ in $\mathrm{dl} 3 \mathrm{3}$ neurons, and had a reduced number of $\mathrm{Ngn} 1+$ progenitor cells in dp2 domain. Ectopic expression of Pax2 and Lbx1 was detected at the positions of $\mathrm{dl} 2-\mathrm{dl} 3$ neurons. $\boldsymbol{B}, \boldsymbol{D}$ $\mathrm{dl} 4^{*}$ indicates ectopic $\mathrm{d} 14$ interneurons derived from dp 2 and $\mathrm{dp} 3$ domains in Olig 3 - / - hindbrain. Expression of Mash1 in the dp3-dp5 domains was not altered. Scale bar, $100 \mu \mathrm{m}$.

loss of Brn3a+CF neurons in the ION. Together, these findings suggested that CRL can be divided into two regions along dorsalventral axis: the $\mathrm{dp} 1$ progenitor domain that gives rise to the precerebellar MF neurons and the ventral Olig3+ progenitor domains that contribute substantially to the formation of precerebellar CF nucleus.

Recent Ptfla-Cre lineage tracing experiments showed that $\mathrm{Brn} 3 \mathrm{a}+$ glutamatergic CF neurons are derived from Ptfla + progenitor cells, and Ptfla-null mutation similarly resulted in the loss of ION (Hoshino et al., 2005; Yamada et al., 2007). In light of our finding that Ptfla was coexpressed with Olig3 in the ventral dp3 domain and a dual requirement of Ptfla and Olig3 for ION formation (Figs. $1 \mathrm{~K}, 2 \mathrm{~A}$ ), we propose that $\mathrm{CF}$ neurons are spe- 

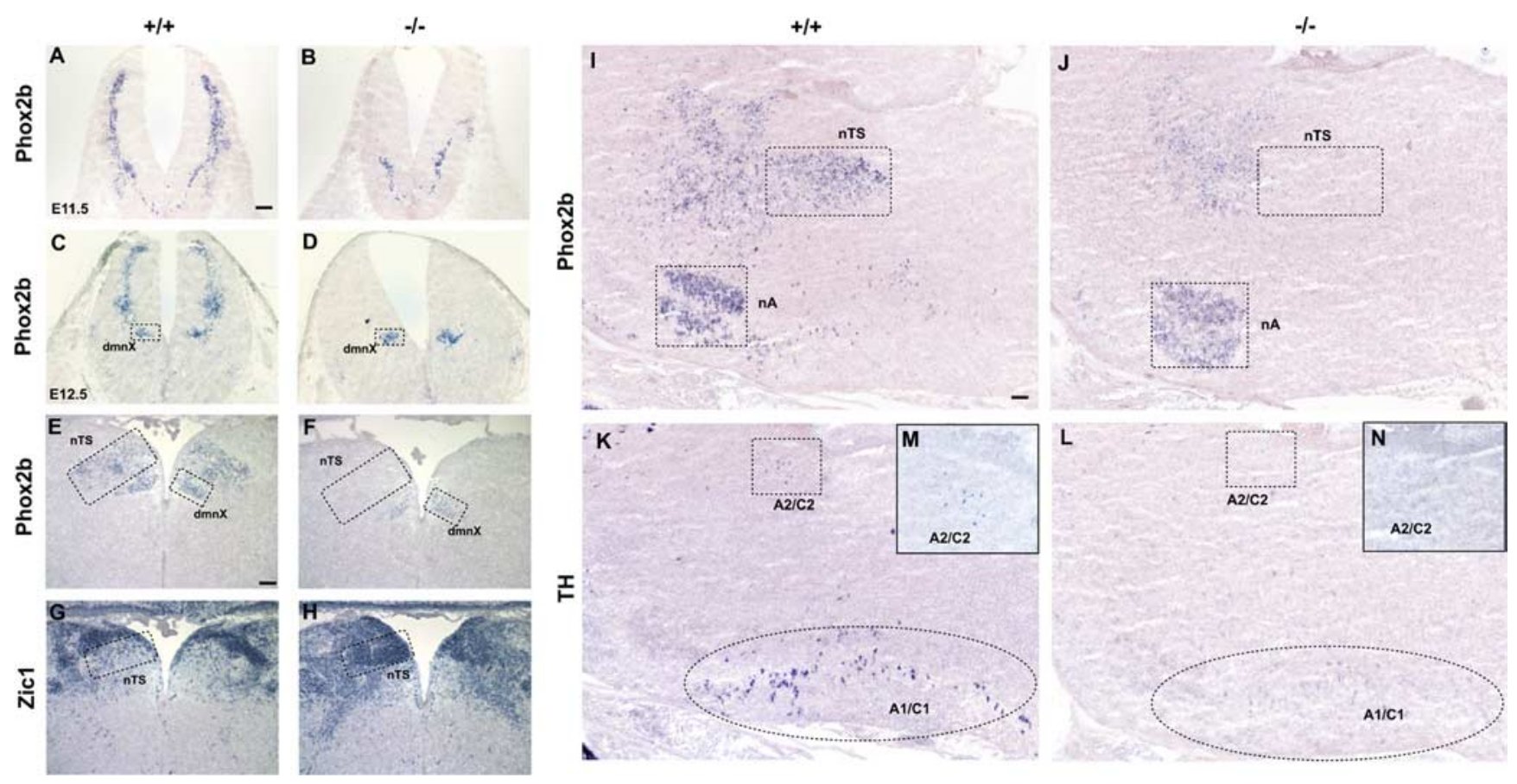

Figure 8. Formation of brainstem (nor)adrenergic centers and first-order relay visceral sensory neurons is dependent on Olig3. $\boldsymbol{A}-\boldsymbol{D}$, Phox $2 b$ expression was examined in the transverse sections of E11.5 $(\boldsymbol{A}, \boldsymbol{B})$ and E12.5 $(\boldsymbol{C}, \boldsymbol{D})$ caudal hindbrains. Dorsal expression of Phox2b was completely inhibited in Olig3 mutants. $\boldsymbol{E}, \boldsymbol{F}$, The nTS labeled with Phox2b was lost in E18.5 Olig3 mutants, whereas the dmnX, located ventral to the nTS structure in wild-type embryos $(\boldsymbol{E})$, still existed in Olig3-/- medulla $(\boldsymbol{F}) . \boldsymbol{G}, \boldsymbol{H}$, Ectopic Zic1 expression was detected in the prospective nTS area in Olig3 mutants. I-L, All E18.5 sagittal sections were oriented with rostral to the left. I, J, Phox2b expression was checked in the sagittal sections. $\boldsymbol{K}, \boldsymbol{L}$, In Olig3 mutants, expression of $T H$ was absent in the (nor)adrenergic centers of medulla, including A1/C1 and A2/C2. $\boldsymbol{M}, \boldsymbol{N}$, High-power images of A2/C2 areas. Scale bars: $\boldsymbol{A}$ (for $\boldsymbol{A}-\boldsymbol{D}), \boldsymbol{E}($ for $\boldsymbol{E}-\boldsymbol{H}), \boldsymbol{I}($ for $\boldsymbol{I}-\boldsymbol{L}), 100 \mu \mathrm{m}$.

cifically derived from the Olig3+/Ptfla overlapping region of the ventral dp3 domain (Fig. $1 \mathrm{~K}$ ). Although Olig3 is required for the fate specification of Brn3a+ excitatory CF neurons, Ptfla activity appears to be essential for the proper migration of $\mathrm{CF}$ neurons. In the absence of Ptfla expression, the generation of $\mathrm{Brn} 3 \mathrm{a}+$ neurons was not compromised, but these neurons failed to migrate into the ION area and subsequently underwent apoptosis (Yamada et al., 2007).

Ptfla is also expressed in dp4 progenitor cells that give rise to inhibitory neurons (Fig. $1 C, F, J, K$ ). In Olig3 mutant embryos, the Ptfla expression was dorsally expanded in association with the dorsal expansion of Pax2+/Lbx1+ GABAergic neurons at the expense of Tlx $3+/ \mathrm{Brn} 3 \mathrm{a}+$ glutamatergic neurons (Figs. 6I,J, 7A-D,G,H). As a result, the formation of Brn3a+ IMS of CF neurons and ION were completely abolished (Fig. 5; supplemental Figs. S1, S2, available at www. jneurosci.org as supplemental material). Collectively, these findings strongly suggested that in the absence of Olig 3 expression, the $\mathrm{dp} 2$ and $\mathrm{dp} 3$ domains were respecified to the $\mathrm{dp} 4$ domain. In contrast, the generation of Brn $3 a+/ T l x 3+$ dI 5 neurons was not affected (Fig. $7 A, B, G, H$ ), indicating that dI5 neurons do not contribute to ION population.

ION is largely composed of glutamatergic excitatory neurons (Brn3a+), but it also contains a small number of GABAergic inhibitory neurons (Fredette et al., 1992). The inhibitory ION neurons may originate from the more ventral Ptfla domain of dorsal caudal hindbrain. The Ptfla + neural progenitor cells in dp4 domain are in close association with the Pax2+ neurons, consistent with the previous reports that Ptfla promotes the fate of GABAergic inhibitory neurons in the dorsal spinal cord and cerebellum (Glasgow et al., 2005; Hoshino et al., 2005).

\section{Olig3 deficiency inhibits the development of the central respiratory center}

Olig3-/ - mutants died at birth and displayed cyanosis, suggesting that Olig3 function is related to the development of the respiratory system. In support of this idea, Olig3 regulates the specification of dI1-dI3 interneurons, which contribute substantially to the diversity of cell types within the respiratory system. Olig3 mutation may affect several regulatory pathways that are important for the development of the respiratory system. First, loss of Olig3 function significantly affected the formation of four precerebellar MF nuclei through Math1 regulatory pathway (Fig. 4). In particular, the LRN is located in the ventrolateral region of the medulla, where the ventral medullary respiratory center resides. Development of LRN neurons might be particularly important for the functioning of respiratory system. Consistent with this idea, Math1-null mice died shortly after birth from respiratory failure (Ben-Arie et al., 1997). Second, absence of Olig3 completely inhibited the generation of Phox $2 b+$ neurons from dI 3 domain and subsequently disrupted the formation of brainstem (nor)adrenergic centers and first-order relay visceral sensory neurons that were critical for respiratory rhythms and cardiovascular control (Fig. 8). It is well known that Phox $2 b$ is an important transcription factor regulating respiratory activity; mutations in Phox $2 b$ are the main disease-defining mutation in human congenital central hypoventilation syndrome (CCHS), leading to life-threatening hypoxia immediately after birth (Amiel et al., 2003). Tlx3-null mice lost the expression of Phox $2 b$ at later embryonic stages and showed a rapid respiratory rate with short inspiratory duration and frequent apnea (Shirasawa et al., 2000; Qian et al., 2001). Third, Olig3 mutation resulted in the misspecification of dI2-dI3 neurons into dI4 interneurons, and Ptfla was 
ectopically expressed in dp2-dp3 domains (Fig. 6I,J). Tlx3 expression in dp3 domain was lost in Olig3 mutant hindbrain (Fig. $7 G, H)$. Previous reports demonstrated that Ptfla promoted neural precursors to differentiate into GABAergic neurons and Tlx3 determined glutamatergic over GABAergic cell fates (Cheng et al., 2004, 2005; Glasgow et al., 2005; Hoshino et al., 2005; Mizuguchi et al., 2006). Consistent with these findings, ectopic expression of Viaat, a GABAergic neuron marker, was detected at the nTS area in E18.5 Olig3-deficient embryos (supplemental Fig. S3G,H, available at www.jneurosci.org as supplemental material). Thus, excess GABAergic neurons existed in Olig3 mutant respiratory circuit, and this could alter the respiratory pattern, offering an alternative explanation for the change of respiratory rhythm in Tlx3 mutant mice. Together, these observations strongly suggest that Olig3 is an important transcription factor regulating the embryonic development of the central respiratory system. Human sudden infant death syndrome (SIDS) is a major cause of infant mortality, but the exact cause of this disease is still unclear. Growing evidence suggests that the impairment of central respiratory control leads to the defect of SIDS patients in response to breath and blood pressure challenges during sleep (Gillan et al., 1989). In addition, one-third of CCHS victims do not carry the mutation of Phox $2 b$ gene (Amiel et al., 2003). Therefore, Olig3 should be a candidate gene for human SIDS and CCHS.

\section{References}

Altman J, Bayer SA (1987a) Development of the precerebellar nuclei in the rat: I. The precerebellar neuroepithelium of the rhombencephalon. J Comp Neurol 257:477-489.

Altman J, Bayer SA (1987b) Development of the precerebellar nuclei in the rat: II. The intramural olivary migratory stream and the neurogenetic organization of the inferior olive. J Comp Neurol 257:490-512.

Altman J, Bayer SA (1987c) Development of the precerebellar nuclei in the rat: III. The posterior precerebellar extramural migratory stream and the lateral reticular and external cuneate nuclei. J Comp Neurol 257:513-528.

Altman J, Bayer SA (1987d) Development of the precerebellar nuclei in the rat: IV. The anterior precerebellar extramural migratory stream and the nucleus reticularis tegmenti pontis and the basal pontine gray. J Comp Neurol 257:529-552.

Ambrosiani J, Armengol JA, Martinez S, Puelles L (1996) The avian inferior olive derives from the alar neuroepithelium of the rhombomeres 7 and 8: an analysis by using chick-quail chimeric embryos. Neuroreport $7: 1285-1288$

Amiel J, Laudier B, Attié-Bitach T, Trang H, De Pontual L, Gener B, Trochet D, Etchevers H, Ray P, Simonneau M, Vekemans M, Munnich A, Gaultier C, Lyonnet S (2003) Polyalanine expansion and frameshift mutations of the paired-like homeobox gene Phox2B in congenital central hypoventilation syndrome. Nat Genet 33:459-461.

Belluardo N, Wu G, Mudo G, Hansson AC, Pettersson R, Fuxe K (1997) Comparative localization of fibroblast growth factor receptor-1, -2 , and -3 mRNAs in the rat brain: in situ hybridization analysis. J Comp Neurol 379:226-246.

Ben-Arie N, Bellen HJ, Armstrong DL, McCall AE, Gordadze PR, Guo Q, Matzuk MM, Zoghbi HY (1997) Math1 is essential for genesis of cerebellar granule neurons. Nature 390:169-172.

Blessing W (1997) The lower brainstem and body homeostasis. New York: Oxford UP.

Bulfone A, Menguzzato E, Broccoli V, Marchitiello A, Gattuso C, Mariani M, Consalez GG, Martinez S, Ballabio A, Banfi S (2000) Barhll, a gene belonging to a new subfamily of mammalian homeobox genes, is expressed in migrating neurons of the CNS. Hum Mol Genet 9:1443-1452.

Cambronero F, Puelles L (2000) Rostrocaudal nuclear relationship in the avian medulla oblongata: a fate map with quail chick chimeras. J Comp Neurol 427:522-545.

Caspary T, Anderson KV (2003) Patterning cell types in the dorsal spinal cord: what the mouse mutants say. Nat Rev Neurosci 4:289-297.

Cheng L, Arata A, Mizuguchi R, Qian Y, Karunaratne A, Gray PA, Arata S, Shirasawa S, Bouchard M, Luo P, Chen CL, Busslinger M, Goulding M,
Onimaru H, Ma Q (2004) Tlx3 and Tlx1 are post-mitotic selector genes determining glutamatergic over GABAergic cell fates. Nat Neurosci 7:510-517.

Cheng L, Samad OA, Xu Y, Mizuguchi R, Luo P, Shirasawa S, Goulding M, Ma Q (2005) Lbx1 and Tlx3 are opposing switches in determining GABAergic versus glutamatergic transmitter phenotypes. Nat Neurosci 8:1510-1515.

Farago AF, Awatramani RB, Dymecki SM (2006) Assembly of the brainstem cochlear nuclear complex is revealed by intersectional and subtractive genetic fate maps. Neuron 50:205-218.

Fedtsova NG, Turner EE (1995) Brn-3.0 expression identifies early postmitotic CNS neurons and sensory neural precursors. Mech Dev 53:291-304.

Fink AJ, Englund C, Daza RA, Pham D, Lau C, Nivison M, Kowalczyk T, Hevner RF (2006) Development of the deep cerebellar nuclei: transcription factors and cell migration from the rhombic lip. J Neurosci 26:3066-3076.

Foletti DL, Scheller RH (2001) Developmental regulation and specific brain distribution of phosphorabphilin. J Neurosci 21:5461-5472.

Fredette BJ, Adams JC, Mugnaini E (1992) GABAergic neurons in the mammalian inferior olive and ventral medulla detected by glutamate decarboxylase immunocytochemistry. J Comp Neurol 321:501-514.

Gillan JE, Curran C, O’Reilly E, Cahalane SF, Unwin AR (1989) Abnormal patterns of pulmonary neuroendocrine cells in victims of sudden infant death syndrome. Pediatrics 84:828-834.

Glasgow SM, Henke RM, MacDonald RJ, Wright CVE, Johnson JE (2005) Ptfla determines GABAergic over glutamatergic neuronal cell fate in the spinal cord dorsal horn. Development 132:5461-5469.

Gowan K, Helms AW, Hunsaker TL, Collisson T, Ebert PJ, Odom R, Johnson JE (2001) Crossinhibitory activities of Ngn1 and Math1 allow specification of distinct dorsal interneurons. Neuron 31:219-232.

Gross MK, Dottori M, Goulding M (2002) Lbx1 specifies somatosensory association interneurons in the dorsal spinal cord. Neuron 34:535-549.

Harkmark W (1954) Cell migrations from the rhombic lip to the inferior olive, the nucleus raphe and the pons. A morphological and experimental investigation of chick embryos. J Comp Neurol 100:115-209.

Helms AW, Johnson JE (2003) Specification of dorsal spinal cord interneurons. Curr Opin Neurobiol 13:42-49.

His W (1891) Die Entwicklung des menschlichen rautenhirms vom ende des ersten bis zum beginn des dritten monats. I. Verlangertes mark. Abhandlungen der koniglicher sachsischen gesellschaft der wissenschaften. Mathematische-physikalische Klasse 29:1-74.

Hoshino M, Nakamura S, Mori K, Kawauchi T, Terao M, Nishimura YV, Fukuda A, Fuse T, Matsuo N, Sone M, Watanabe M, Bito H, Terashima T, Wright CV, Kawaguchi Y, Nakao K, Nabeshima Y (2005) Ptfla, a bHLH transcriptional gene, defines GABAergic neuronal fates in cerebellum. Neuron 47:201-213.

Jessell TM (2000) Neuronal specification in the spinal cord: inductive signals and transcriptional codes. Nat Rev Genet 1:20-29.

Landsberg RL, Awatramani RB, Hunter NL, Farago AF, DiPietrantonio HJ, Rodriguez CI, Dymecki SM (2005) Hindbrain rhombic lip is comprised of discrete progenitor cell populations allocated by Pax6. Neuron 48:933-947.

Lee KJ, Jessell TM (1999) The specification of dorsal cell fates in the vertebrate central nervous system. Annu Rev Neurosci 22:261-294.

Lumsden A, Krumlauf R (1996) Patterning the vertebrate neuraxis. Science 274:1109-1115.

Machold R, Fishell G (2005) Math1 is expressed in temporally discrete pools of cerebellar rhombic-lip neural progenitors. Neuron 48:17-24.

Mizuguchi R, Kriks S, Cordes R, Gossler A, Ma Q, Goulding M (2006) Ascl1 and Gsh1/2 control inhibitory and excitatory cell fate in spinal sensory interneurons. Nat Neurosci 9:770-778.

Morin X, Cremer H, Hirsch MR, Kapur RP, Goridis C, Brunet JF (1997) Defects in sensory and autonomic ganglia and absence of locus coeruleus in mice deficient for the homeobox gene Phox2a. Neuron 18:411-423.

Müller T, Brohmann H, Pierani A, Heppenstall PA, Lewin GR, Jessell TM, Birchmeier C (2002) The homeodomain factor lbxl distinguishes two major programs of neuronal differentiation in the dorsal spinal cord. Neuron 34:551-562.

Müller T, Anlag K, Wildner H, Britsch S, Treier M, Birchmeier C (2005) The bHLH factor Olig3 coordinates the specification of dorsal neurons in the spinal cord. Genes Dev 19:733-743. 
Pattyn A, Morin X, Cremer H, Goridis C, Brunet JF (1999) The homeobox gene Phox $2 \mathrm{~b}$ is essential for the development of autonomic neural crest derivates. Nature 399:366-370.

Pattyn A, Goridis C, Brunet JF (2000) Specification of the central noradrenergic phenotype by the homeobox gene Phox2b. Mol Cell Neurosci 15:235-243

Qian Y, Fritzsch B, Shirasawa S, Chen CL, Choi Y, Ma Q (2001) Formation of brainstem (nor)adrenergic centers and first-order relay visceral sensory neurons is dependent on homeodomain protein Rnx/Tlx3. Genes Dev 15:2533-2545.

Qian Y, Shirasawa S, Chen CL, Cheng L, Ma Q (2002) Proper development of relay somatic sensor neurons and D2/D4 interneurons requires homeobox genes Rnx/Tlx3 and Tlx1. Genes Dev 16:1220-1233.

Schaeren-Wiemers N, Gerfin-Moser A (1993) A single protocol to detect transcripts of various types and expression levels in neural tissue and cultured cells: in situ hybridization using digoxigenin-labeled cRNA probes. Histochemistry 100:431-440.

Schüller U, Kho AT, Zhao Q, Ma Q, Rowitch DH (2006) Cerebellar 'transcriptome' reveals cell-type and stage-specific expression during postnatal development and tumorigenesis. Mol Cell Neurosci 33:247-259.

Shirasawa S, Arata A, Onimaru H, Roth KA, Brown GA, Horning S, Arata S,
Okumura K, Sasazuki T, Korsmeyer SJ (2000) Rnx deficiency results in congenital central hypoventilation. Nat Genet 24:287-290.

Sieber MA, Storm R, Martinez-de-la-Torre M, Müller T, Wende H, Reuter K, Vasyutina E, Birchmeier C (2007) Lbxl acts as a selector gene in the fate determination of somatosensory and viscerosensory relay neurons in the hindbrain. J Neurosci 27:4902-4909.

Sotelo C (2004) Cellular and genetic regulation of the development of the cerebellar system. Prog Neurobiol 72:295-339.

Takebayashi H, Ohtsuki T, Uchida T, Kawamoto S, Okubo K, Ikenaka K, Takeichi M, Chisaka O, Nabeshima Y (2002) Non-overlapping expression of Olig3 and Olig2 in the embryonic neural tube. Mech Dev 113:169-174.

Wang VY, Rose MF, Zoghbi HY (2005) Math1 expression redefines the rhombic lip derivatives and reveals novel lineages within the brainstem and cerebellum. Neuron 48:31-43.

Xiang M, Gan L, Zhou L, Klein WH, Nathans J (1996) Targeted deletion of the mouse POU domain gene Brn-3a causes selective loss of neurons in the brainstem and trigeminal ganglion, uncoordinated limb movement, and impaired suckling. Proc Natl Acad Sci U S A 93:11950-11955.

Yamada M, Terao M, Terashima T, Fujiyama T, Kawaguchi Y, Nabeshima Y, Hoshino M (2007) Origin of climbing fiber neurons and their developmental dependence on Ptfla. J Neurosci 27:10924-10934. 